\title{
On the Non-reception of the Food Systems Summit in Europe
}

\author{
Jan Douwe van der Ploeg ${ }^{1}$
}

Published online: 11 October 2021

(c) Society for International Development 2021

\begin{abstract}
This article focuses on the indifference and annoyance that preceded and followed the UN Food Systems Summit and its preparatory meetings. It argues that, from a European perspective, the Food Systems Summit agenda does not entail anything new, whilst its impact will negatively fire back by further increasing dependencies and fragilities in the food system.
\end{abstract}

Keyword Hegemony $\cdot$ National dialogue $\cdot$ Nomenklatura $\cdot$ Inverse relation between words and facts

If there is anything remarkable at all about the reception of the United Nations Food Systems Summit (UNFSS) in Europe, it is that it went largely unnoticed. Maybe 'unnoticed' is not even the right word. It was noted of course, ${ }^{1}$ but went largely neglected. It did not generate any interest, especially among the majority of the general public (which is actually a remarkable contrast with previous Food Summits and the annual World Food Days). The pre-Summit, which was held in Rome in July 2021, failed to mobilize any public interest and support and hardly attracted any media coverage. The Summit itself (23 September 2021) neither stirred up much interest.

There was, of course, some public and private involvement in what are known as the 'national dialogues' that preceded the pre-Summit. Vested interests: farmers' unions, agro-industries, banks, research networks and agricultural universities all made their presence felt. But this was all carefully orchestrated, and the participating actors merely followed scripts that reflected their own, narrow, interests. There were promises of money, business and hegemony, so they felt that they had to be there. They all also echoed the same message: one that was meant to mobilize interest but which, in the end, just sounded hollow. The 'process' (of the national dialogues preceding the pre-Summit) and the

\footnotetext{
1 Although, the European Coordination of Via Campesina, several members of the European Parliament, NGOs such as Crocevia and Associazione Rurale Italiana (ARI) in Italy and the Voedsel Anders Coalition in the Netherlands did pay critical attention to the pre-Summit.
}

Jan Douwe van der Ploeg

jandouwe.vanderploeg@wur.nl

1 Wageningen University, Wageningen, The Netherlands input of those who actually participated was characterized as ambitious, game-changing, transformative, solution-oriented and inclusive. ${ }^{2}$ Yet this was not reflected in any popular support (or even interest). On the contrary, the many potential audiences appeared to be indifferent (and sometimes critically distant). As a typical example, the national dialogue in the Netherlands mainly involved 'Dutch organisations active in the area of food and nutritional security in lowand middle-income countries' [italics added]. ${ }^{3}$ The organization and development of European agriculture and European agricultural policy was not the object of the dialogue, although its negative impact on the world food situation is undeniable. The dialogue was all about 'others' (in low- and middle-income countries) and how they should be 'helped'. It is equally notable that Parliament was bypassed: 'There was no note to parliament. The Dutch contribution to the UNFSS is based on existing policy. The Netherlands supports the whole summit process, and does not foresee an outcome that is different from the existing government position on food systems. ${ }^{4}$ Together, the continuity of existing policies and the simultaneously declared game-changing nature of the UNFSS process make for an intriguing combination.

Throughout Europe, large segments of civil society are passionately involved in debates about farming, food processing and the associated global relations of dependency

\footnotetext{
2 This is, in historical terms, an interesting phenomenon. Whether or not a new product, approach or programme is to be seen as gamechanging, etc., or not, is normally assessed ex-post, not ex-ante. Beyond that it critically depends on the judgment of the end-users. Now it is being claimed before the event.

3 https://www.nlfoodpartnership.com/food-systems-transformation/ dutch-food-systems-summit-preparations/.

${ }^{4}$ Notes from the Dutch Information meeting for the UNFSS, 5 July.
} 
and inequality. ${ }^{5}$ Equally large parts of the farming population are developing new practices that substantially, and intentionally, deviate from the script that capital tries to impose upon the production, processing, distribution, and consumption of food. ${ }^{6}$ It might well be argued that in, and through, all these debates and new practices some form of food sovereignty is being constructed, step-by-step, across Europe. This process is occurring in full recognition of the international dimension of the food question and the associated responsibilities.

Yet, this huge reservoir of critical civil society organizations and farmers developing new alternatives was not involved in the 'national dialogues' - mostly they were not even invited along.

Thus, the preparations (at least in Europe) for the preSummit were in effect a 'closed shop', which not surprisingly, developed an agenda that hardly entailed anything daring. The agenda neither triggered any popular support and/or acclamation after the pre-Summit. Nonetheless, the organizers of the pre-Summit blandly continue talking about a 'people's summit'. The process clearly exhibits an inverse relation between words and facts.

The agenda and rhetoric of the pre-Summit (and the Summit to come) centre on technological fixes and enlarging the spaces for entrepreneurial initiatives. They stem from a nomenklatura ${ }^{7}$ that claims that everything it proposes is game-changing, inclusive, and the like, whilst, to date, it has been unable to resolve the many problems for which, after 50 plus years of hegemony, it is largely responsible.

Everyone who is more or less familiar with debates about farming will recognize that there is hardly anything new in the seemingly overwhelming number of initiatives, actions, and proposals that are taken from different sources. Much of it is about practices already tried out on a minor scale in different places around the world. ${ }^{8}$ What is essentially lacking,

\footnotetext{
5 Many NGOs, but also the churches, labour unions, Fair Trade organizations, political parties of the left, women organizations, etc., play an important role in this respect.

6 These practices include the elaboration of multifunctionality, the application of agroecological principles, the construction of peasant markets, the on-farm processing of agricultural products into food, etc., etc.

7 The 'nomenklatura' is the network of people who are in charge in the current food systems. A typical exponent is Ms. Fresco, VicePresident of the Scientific Committee of the UNFSS, board member of Syngenta, former board member of Unilever and RABO Bank, and currently President of Wageningen University in the Netherlands.

8 As a matter of fact, Wageningen University has developed, over the last two decades or so, a tradition in co-opting critical initiatives and practices, especially when public funding comes available. The 'take over' is accompanied by a new lexicon (organic farming for instance became 'rational organic farming', indicating that it was superior to the existing 'irrational' practices of organic farmers) and needing a treatment in which 'homeopathic dilution' is central ('adding' some chemical fertilizer to organic farming is just 'rational'; a bit of genetic engineering can very much 'help' agroecology, etc., etc.).
}

though, are proposals on how to forge these many initiatives into a coherent and comprehensive programme for effective change. Such a programme could and should help to protect each single initiative from the destructive dynamics of an unaltered world market and to align them in such a way that synergic effects emerge (instead of one initiative neutralizing the positive effect of another one).

A number of burning questions seem to remain completely outside of the UNFSS's field of vision: where to produce more, ${ }^{9}$ who should do so, how they are going to do so, for whom, and what will be done with the income rendered by increasing (or reorganizing) production. All these questions are at the forefront of critical debates in civil society. The approach also remains worryingly silent on the endogenous potentials entailed in most agricultural systems. Unlocking such potentials, through e.g. market regulation, enlarging the bargaining power of peasants' and farmers' movements, improving the position of women and youth, land reforms, cooperative seed banks, etc., remains at the margins. 'Development', instead, is to be brought in from the outside - through new technologies, an inflow of capital and new organizational models (typically public-private partnerships). This makes for an elitist and noninclusive type of rural development.

Underneath the dazzling array of proposals, unasked questions, and exalted wording there is, however, a clear focus. When asked, during the opening panel of the preSummit, to indicate the key axes of the UNFSS agenda, Ms. Fresco (talking as Vice-President of the Scientific Committee of the UNFSS) pointed to 'genetics and digitalization': genetics to liberate agricultural and food production from the boundaries entailed in living nature and digitalization to bypass the conditions and limits represented by the population economically active in agriculture. Over the ages, farming has been the evolving encounter, interaction and mutual transformation of 'man and living nature'. ${ }^{10}$ Ms. Fresco's words make it clear that the UNFSS wishes to draw a line under all this: without explicitly saying so, it seeks an agriculture in which living nature and labour are no longer the key pillars. Genetics and digitalization, respectively, are seen as taking their place. This echoes the project that is central to many public and private research institutions (of which Wageningen University is a key player): constructing an agriculture without farmers, an agriculture that simultaneously offers immense investment opportunities for capital. ${ }^{11}$

\footnotetext{
9 http://www.pablotittonell.net/2015/06/whos-producing-our-food/.

${ }^{10}$ In the rich literature on the history of farming and agricultural sciences this is a standing expression. 'Man' here evidently refers to mankind, or more precisely: to all actors involved in agricultural production. In the literature, the encounter, etc., of 'man and living nature' (of social and natural resources) is also referred to as 'co-production' (Toledo 1992; Mazoyer and Roudart 2006).

${ }^{11}$ Fresco and Poppe (2016). This publication outlines a European Food System in which (a reduced number of) farmers only exist as franchise holders for the food industry.
} 


\section{The Likely Repercussions in Europe}

Although the UNFSS is mainly oriented at problems in the Global South, ${ }^{12}$ its agenda will also affect Europe. If this agenda were to be effectively implemented, it would not only imply a huge restructuring of the agricultural sectors of the Global South, but it would also fire back on Europe, in several ways. First, it would further accentuate the international division of labour in agriculture and food production. It would continue to enlarge the parts of agriculture already oriented towards agro-exports and create new ones, in both the Global South and in the Global North. This would inevitably marginalize large swathes of rural areas and their population active in agriculture and simultaneously enlarge the centrality of food industries, food processing and long-distance trade. More generally speaking, the UNFSS agenda will result in new and enlarged webs of dependencies and, consequently, in ever so many new vulnerabilities (as witnessed during the COVID-19 pandemic). Second, the UNFSS agenda will spur technology-driven intensification. As indicated, it calls for moves towards an agriculture without farmers. An agriculture that is legitimized because it represents high yield levels: assumedly a sine qua non for 'feeding the world'. Over the last five decades the 'old continent' has witnessed several such jumps. They induced the critical attitudes vis-a-vis agriculture and food production that are now widespread throughout Europe.

Olive-oil production provides a recent and telling example of technologically-driven intensification based around genetics and digitalization. Newly engineered cultivars allow for very high yields and for the digitally controlled mechanization of pruning and harvesting. However the 'optimally' producing trees also need 'optimal conditions'. Consequently, olive oil production is increasingly becoming concentrated in fertile valleys, with flat land and abundant availability of irrigation water. This means that olive oil production in the hilly areas of Europe is seriously threatened and that the many farms and farmers located there are losing their raison d'être. Thus, 'growth' combines with contraction in already marginal areas and the conversion of land which may be more suitable for arable production. A zero sum game? Or even less? Typically, experience shows that the new, 'optimal' trees need to be replaced (and thus bought anew) after just five to seven years. So, such technological development in today's agriculture is clearly far from neutral. It reshuffles the fates of man and the land, whilst introducing new vulnerabilities.

The eventual implementation of the UNFSS agenda will also push farming further along the road of increased fossil energy use (as in the case of olive oil), especially since the associated (and much promoted) digitalization requires the

12 Obesity evidently being the exception. energy-consuming production of chips for the required hardware and massive cooling of the many servers needed to run the new digital systems. All this implies that it is difficult, for European people, especially those living in and gaining their livelihoods from rural areas, to experience much enthusiasm for the UNFSS approach. ${ }^{13}$

\section{The Struggle for Hegemony}

Although the consequences of the UNFSS-agenda in Europe are worrisome, its real significance and danger reside elsewhere. ${ }^{14}$ That is, in its attempt to re-establish hegemony. As argued, food production, processing, distribution, and consumption governed by capital has increasingly lost its credibility. ${ }^{15}$ The same applies to those parts of science that align themselves with capital's scripts. In the meantime, agricultural policies have shown themselves to be unable to address the many frictions and problems that result from the dominant development trajectories. Together capital, science and the state constitute a food regime that is losing its hegemony. People no longer trust the projects and proposals stemming from this regime. This is reflected in the blossoming of the many grass-root level searches for alternatives.

The UNFSS represents a concerted action meant to reconquer this hegemony. 'The creation of trust [...] in the management of the food problem is priority number one', according to Ms. Fresco in a press release from Wageningen University. ${ }^{16}$ This is to be done by means of, and through, 'scientific diplomacy'. ${ }^{17}$ Assumedly, this diplomacy will aim to convince the rest of the world that the many-sided critiques of the current food regime are grounded in a series of misunderstandings, in confusing 'facts' with 'emotions',

\footnotetext{
${ }^{13}$ Proponents of the UNFSS justify their agenda by referring to the SDGs, especially the enlargement of total food production so as 'to feed the world'. Since Europe is more than self-sufficient in food, this motive does not apply here. Ironically, though, the UNFSS agenda could very well bring, as an unintended consequence, increased agricultural and food production that will negatively impact on agricultural production in the Global South.

${ }^{14}$ I think that the attempts to impose such an agenda will ultimately be countered by popular movements and /or limited by the new contradictions they generate.

15 Ironically, its last ally, the segment of industrialized farmers, is currently deserting this sinking ship and aligning itself under the banner of right-wing, conservative populism.

16 https://klimaatweb.nl/nieuws/oproep-tot-een-gestructureerde-dialo og-om-voedselsystemen-effectief-te-hervormen/.

17 This concept is grounded on the strange notion of science as a normative framework that is able to specify the way society is to be organized and governed. This is in line with the notion of science used in 'Science and innovations for food systems change: Opportunities for the UN Food Systems Summit' by von Braun, Afsana, Fresco and Hassan (July 5, 2021) which argues that 'science and research
} 
and in opting for morally abject positions (such as 'promoting hunger'). ${ }^{18}$ Those who are, or have been, working in Wageningen University are more than familiar with this kind of 'diplomacy'. Simultaneously, this scientific diplomacy seems to be clearly meant to open up new spaces for capital. For.the mobilization of the private sector, according to Ms. Fresco in the same press release,.is decisive for the public cause [i.e. the transformation of food systems].. This position is legitimized with a remarkable bêtise: There is no modern country in this world where the government is baking the bread. (!).

It is true, there are no state apparatuses (any more) that are directly involved in providing bread to their populations. However, it is fallacious to imply that this means that capital should assume a decisive role. Take Europe. Here there are more and more local and regional networks with artisanal bakeries using locally milled grain produced by agroecological farmers which provide us with our bread, and there are also local brewers who supply us with good beers made from locally grown cereals (that even win the prize for best beer of the world). Moving capital to the margins in the provisioning of foods and drinks would definitely make for a better world than putting it centre stage.

\section{References}

Fresco, Louise O., and Krijn J. Poppe. 2016. Towards a Common Agricultural and Food Policy. Wageningen: Wageningen University.

Mazoyer, Marcel, and Laurence Roudart. 2006. A history of world agriculture: From the neolithic age to the current crisis. Routledge.

Toledo, Víctor M.1990. The ecological rationality of peasant production. Agroecology and Small Farmer Development: 51-58, Miguel A. Altieri and S. Hecht (eds.) Boca Raton, FL: CRC Press.

Publisher's Note Springer Nature remains neutral with regard to jurisdictional claims in published maps and institutional affiliations.
Footnote 17 (continued)

are fundamental drivers of innovation. All three-science, research and innovation-are essential to accelerate the transformation to healthier, more sustainable, more equitable, and more resilient food systems' (p. 9). The authors ascribe a central and decisive position to science. This implies that is only 'implementation' that separates scientific innovations from a completely re-ordered food regime. What typically remains outside of the equation are structural reforms, social movements, and the emancipatory aspirations of hundreds of million peasants who often desperately seek to enlarge their production in order to improve their livelihoods.

18 The previous President of Wageningen University denounced scholars advocating agroecology and organic farming of 'being responsible for hunger in the world'. 